\title{
Biomechanical evaluation of subcrestal dental implants with different bone anchorages
}

Bruno Salles SOTTO-MAIOR(a) Camila de Andrade LIMA ${ }^{(b)}$ Plínio Mendes SENNA ${ }^{(c)}$ Germana de Villa CAMARGOS(b) Altair Antoninha DEL BEL CURY(b)

(a) Department of Restorative Dentistry, Dental School, Universidade Federal de Juiz de Fora - UFJF, Juiz de Fora, MG, Brazil.

(b) Department of Prosthodontics and Periodontology, Piracicaba Dental School, University of Campinas - UNICAMP, Piracicaba, SP, Brazil.

(c)Department Health Sciences Center, Unigranrio University, Duque de Caxias, Rio de Janeiro, Brazil.

Declaration of Interests: The authors certify that they have no commercial or associative interest that represents a conflict of interest in connection with the manuscript.

Corresponding Author:

Bruno Salles Sotto-Maior

E-mail: bruno.sotto@ufjf.edu.br

DOI: 10.1590/1807-3107BOR-2014.vol28.0023 Epub XXXXX, 2014

Submitted: Aug 14, 2013

Accepted for publication: Feb 17, 2014

Last revision: May 29, 2014

\begin{abstract}
This study evaluated the biomechanical influence of apical bone anchorage on a single subcrestal dental implant using three-dimensional finite element analysis (FEA). Four different bone anchorage designs were simulated on a posterior maxillary segment using one implant with platform switching and internal Morse taper connection as follows: $2 \mathrm{~mm}$ subcrestal placement with (SW) or without (SO) the implant apex engaged into the cortical bone or position at bone level with anchorage only in the crestal cortical (BO) bone or with bicortical fixation (BW). Each implant received a premolar crown, and all models were loaded with $200 \mathrm{~N}$ to simulate centric and eccentric occlusion. The peak tensile and compressive stress and strain were calculated the crestal cortical, trabecular, and apical cortical bone. The vertical and horizontal implant displacements were measured at the platform level. FEA indicated that subcrestal placement (SW and SO) created lower stress and strain in the crestal cortical bone compared with crestal placement (BO and BW models). The SW model exhibited lesser vertical and horizontal implant micromovement compared with the $\mathrm{SO}$ and $\mathrm{BO}$ models under eccentric loading; however, stress and strain were higher in the apical cortical bone. The BW model exhibited the lowest implant displacement. These results indicate that subcrestal placement decreases the stress in the crestal cortical bone of dental implants, regardless of apical anchorage; however, apical cortical anchorage can be effective in limiting implant displacement. Further studies are required to evaluate the effects of possible remodeling around the apex on the success of subcrestal implants.
\end{abstract}

Keywords: Dental Implants; Dental Stress Analysis; Finite Element Analysis.

\section{Introduction}

Dental implants are widely used to replace missing teeth, and their clinical success is dependent on the primary stability achieved during implant placement. ${ }^{1}$ The threshold of movement within the alveolar bone should be $150 \mu \mathrm{m}$ so that it does not interfere with the healing process. ${ }^{2}$ However, in regions of poor bone quality, such as the posterior maxilla, ${ }^{3}$ adequate primary stability cannot be achieved at bone level, necessitating subcrestal placement. ${ }^{4}$ Moreover, this deeper position may also be indicated when there is limited interocclusal height for the restoration and for an esthetic emergence profile. ${ }^{5,6}$ 
Subcrestal implant placement seems to result in more efficient crestal bone preservation when associated with Morse taper connection and platform switching. ${ }^{78,9}$ Although a previous study using finite element analysis (FEA) reported that the peak compressive stress at the crestal cortical bone was higher around subcrestal implants than around implants placed at bone level, ${ }^{10}$ other studies reported that subcrestal placement displaces the stress away from the crestal cortical bone. ${ }^{11,12}$ Therefore, this lower stress concentration in the crestal cortical bone can explain the occurrence of osseointegration coronal to the abutment-fixture interface in cases of subcrestal implant placement with Morse taper connection. ${ }^{6}$

However, in cases of subcrestal implant placement in the maxilla, the implant apex can be engaged into the cortical bone of the nasal or maxillary sinus floor. Bicortical fixation of bone level implants improves primary stability and decreases the stress in the bone, ${ }^{13}$ however, the influence of apical anchorage of subcrestal implants on stress distribution remains unknown. The change in the fulcrum from the implant cervix toward the apical region may change the stress and strain distribution within the bone and affect its resistance to micromovement.

Therefore, given the limited information currently available on subcrestal implant placement, this study was conducted to evaluate the influence of apical bone anchorage for a single subcrestal dental implant on bone stress and strain and resistance to micromovement using three-dimensional FEA.

\section{Methodology}

Three tri-dimensional models of a posterior maxillary segment were developed using the SolidWorks 2011 3D software (SolidWorks Corp., Concord, USA). The models were of different heights $(11,13$, and 15 $\mathrm{mm}$ ) and included a 1-mm-thick uniform cortical bone layer. ${ }^{14}$ Subsequently, a computer-aided design (CAD) model (Cone Morse Titamax EX; Neodent, Curitiba, Brazil) of a $4.0 \times 11-\mathrm{mm}$ Morse taper connection cylindrical implant was combined with one of the maxillary models to allow the construction of four different cortical bone anchorage designs (Figure 1): $2 \mathrm{~mm}$ subcrestal placement with (SW) or without (SO) the implant apex engaged into the cortical bone or posi- tion at the bone level with anchorage only in the crestal cortical bone (BO) or with bicortical fixation (BW).

After implant positioning, a 3.3-mm diameter abutment CAD model (Munhão Universal CM; Neodent, Curitiba, Brazil) was imported into each model and aligned to the implant. To compensate the implant depth and maintain the same crown height, a 1.5-mm-high abutment was used on the bone level implants and a 3.5-mm-high abutment was used on the subcrestal implants (Figure 1). Next, a solid-display stereolithographic image of a second premolar crown, based on cone-beam computed tomography images (Kodak 9000 3D Extraoral Imaging System; Carestream Dental LLC, Atlanta, USA), was positioned on each abutment, simulating an acrylic resin crown with a $50-\mu$ m cement layer. ${ }^{15}$

After construction, the four models were exported to ANSYS Workbench FEA software (ver. 13.0; Swanson Analysis Inc., Houston, USA) for the analysis of peri-implant stress and strain and implant micromovement under load. Cortical and trabecular bone were considered anisotropic, homogeneous, and linearly elastic, while titanium, cement, and acrylic resin were considered isotropic, homogeneous, and linearly elastic. ${ }^{16}$ The mechanical properties are listed in Table 1.

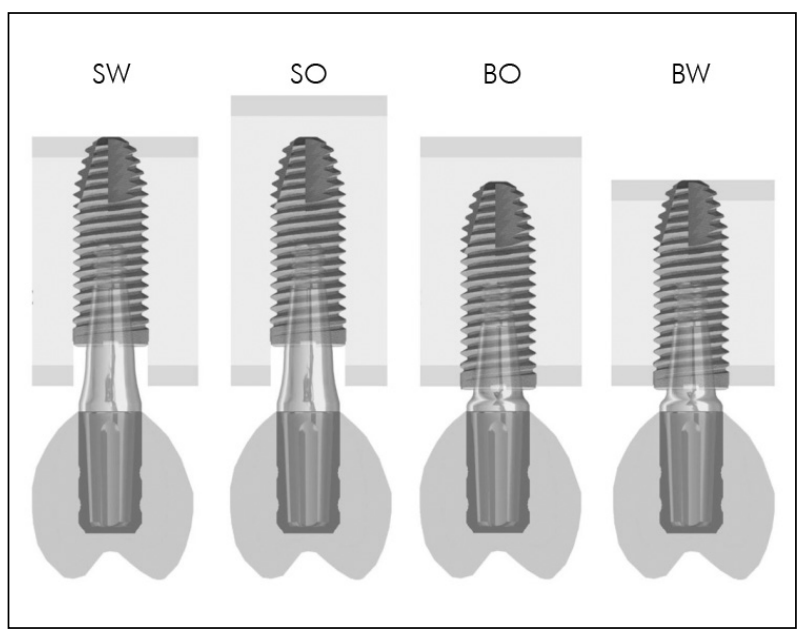

Figure 1. Using a 1-mm-thick cortical layer and different trabecular bone heights, four models are created using one $4.0 \times 11-\mathrm{mm}$ implant with platform switching and internal Morse taper connection. Implants were positioned $2 \mathrm{~mm}$ subcrestally with (SW) or without (SO) apical engagement into the cortical bone or positioned at the bone level with anchorage only in the crestal cortical bone (BO) or with bicortical fixation (BW). 
Table 1. Mechanical properties of the materials included in finite element analysis.

\begin{tabular}{|c|c|c|c|}
\hline & $\begin{array}{l}\text { Young's modulus } \\
\text { (MPa) }\end{array}$ & $\begin{array}{l}\text { Shear modulus } \\
\text { (MPa) }\end{array}$ & $\begin{array}{l}\text { Poisson's } \\
\text { ratio }\end{array}$ \\
\hline \multirow{3}{*}{$\begin{array}{l}\text { Cortical } \\
\text { bone }\end{array}$} & 12,600 & 4,850 & $\begin{array}{ll}V_{x y} & 0.30\end{array}$ \\
\hline & 12,600 & 5,700 & $\begin{array}{ll}V_{y z} & 0.39\end{array}$ \\
\hline & 19,400 & 5,700 & $V_{x z} \quad 0.39$ \\
\hline \multirow{3}{*}{$\begin{array}{l}\text { Trabecular } \\
\text { bone }\end{array}$} & 1,150 & 6,800 & $\begin{array}{ll}V_{x y} & 0.001\end{array}$ \\
\hline & 2,100 & 4,340 & $\begin{array}{ll}V_{y z} & 0.32\end{array}$ \\
\hline & 1,150 & 6,800 & $\begin{array}{ll}V_{x z} & 0.05\end{array}$ \\
\hline Titanium & 104,000 & 38,800 & 0.34 \\
\hline Cement & 17,000 & 14,500 & 0.30 \\
\hline Acrylic resin & 1,800 & 1,700 & 0.30 \\
\hline
\end{tabular}

The subscripts $x, y$, and $z$ correspond to the axis of the global coordinate system.

$E=$ Young's modulus, $G=$ Shear modulus, $V=$ Poisson's ratio

To improve accuracy and ensure the comparability of results, the analysis was accomplished by mesh refinement at a $5 \%$ level. The mesh was generated with $0.6-\mathrm{mm}$ quadratic tetrahedral elements of 10 nodes (ANSYS solid187), enabling the simulation of irregular structures. A frictional contact coefficient between bone and implant surfaces of 0.3 was used, while all other contacts were considered perfectly bonded. ${ }^{17}$ The models were constrained in all directions at nodes on the mesial and distal borders.

The models were loaded with $200 \mathrm{~N}$ divided over three $1.5-\mathrm{mm}^{2}$ areas (at the lingual and buccal sides on top of the lingual cusp and at the grinding ridge of the buccal cusp), and the load was applied perpendicular to the surfaces to simulate centric occlusion. ${ }^{18}$ To simulate lateral excursion, a 200-N load was applied to the middle of the grinding ridge of the buccal cusp. ${ }^{18}$

The principal stress was computed at the crestal cortical, trabecular, and apical cortical bone. This offers the possibility of distinguishing between tensile and compressive stresses, ${ }^{10}$ the maximum principal stress represents the peak tensile stress and the minimum principal stress assigns the peak compressive stress. In addition, bone strain was computed and horizontal and vertical implant displacements measured at the platform level.

\section{Results}

On centric loading, FEA showed that subcrestal placement (SW and SO) decreased the peak compres-
Table 2. Peak tensile and compressive stresses (MPa) and maximum strain $(\mu \mathrm{m})$ in the crestal cortical, trabecular, and apical cortical bone measured under centric loading simulations.

\begin{tabular}{lcccc}
\hline Region & Model & $\begin{array}{c}\text { Peak tensile } \\
\text { stress }\end{array}$ & $\begin{array}{c}\text { Peak compressive } \\
\text { stress }\end{array}$ & Strain \\
\hline Cortical & SW & 87.2 & 44.3 & 0.0013 \\
bone & SO & $8.8^{*}$ & 18.8 & $0.0004^{*}$ \\
& BO & 51.3 & $233.9^{*}$ & 0.0037 \\
& BW & 39.4 & 78.1 & 0.0024 \\
Trabecular & SW & $89.3^{*}$ & 66.7 & $0.2260^{*}$ \\
bone & SO & 23.6 & 48.2 & 0.1220 \\
& BO & 13.5 & 41.2 & 0.0346 \\
& BW & 12.8 & $11.6^{*}$ & 0.0720 \\
Titanium & SW & $106.9^{*}$ & $403.1^{*}$ & $0.0110^{*}$ \\
& SO & 6.1 & 6.1 & 0.0002 \\
& BO & 4.6 & 5.6 & 0.0002 \\
& BW & 26.3 & 61.1 & 0.0018 \\
\hline
\end{tabular}

SW = subcrestal implant with apex anchored in cortical bone; $\mathrm{SO}=$ subcrestal implant anchored only in trabecular bone; $\mathrm{BO}=$ bone level implant anchored only in the crestal cortical bone; $\mathrm{BW}=$ bone level implant with bicortical fixation; ${ }^{*}$ indicates a significant difference between models.

sive stress at the crestal cortical bone and transferred it toward the trabecular bone (Table 2). However, the SW model exhibited a higher peak tensile stress and strain at the crestal cortical and trabecular bone and high compressive stress at the apical cortical bone (Figure 2).

On eccentric loading, the subcrestal implants (SW and $\mathrm{SO}$ ) transferred the compressive stress from the crestal cortical toward the trabecular bone (Table 3) more efficiently. However, the peak compressive stress at the cortical bone around the apex of the SW model was almost 8.5 times higher than that around the apex of the BW model (Figure 3).

The vertical and horizontal displacements that occurred when the implants were subjected to centric and eccentric loading are presented in Figure 4. The SW model exhibited lower micromovement compared with the BO model under eccentric loading, while the $\mathrm{SO}$ and $\mathrm{BW}$ models exhibited the highest and lowest implant displacement, respectively, under both loading simulations.

\section{Discussion}

The cortical bone is responsible for the distribution and transmission of occlusal forces to the peri-implant bone tissue. ${ }^{19}$ Therefore, subcrestal implants that are not 


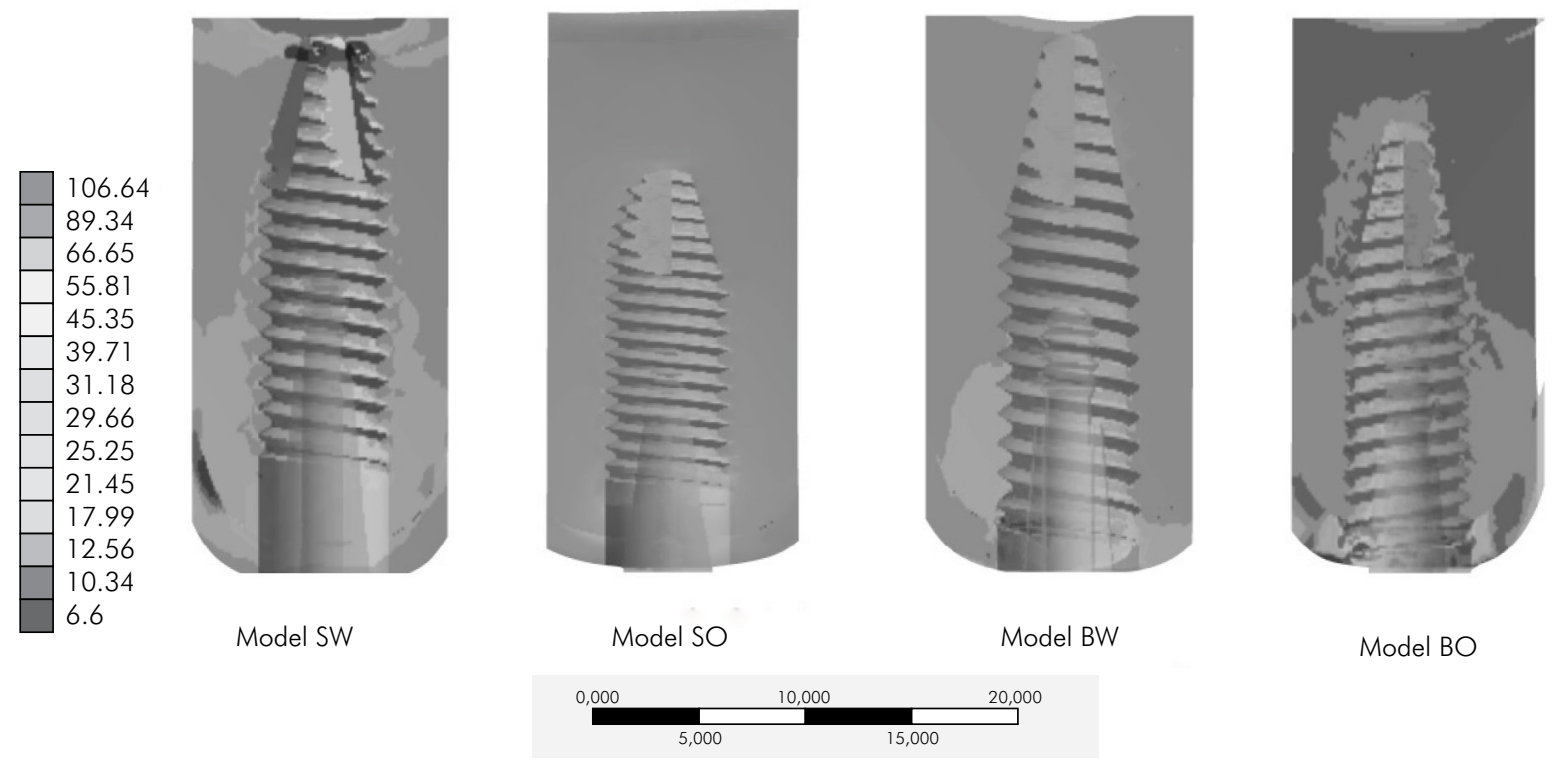

Figure 2. Compressive stress (MPa) around implants with different anchorage designs under centric loading.

engaged in the crestal cortical bone exhibit a biomechanical behavior different from that exhibited by implants placed at the crestal level. In the present study, engagement of the apex into the cortical bone decreased the displacement of subcrestal implants, albeit at the cost of higher stress in the bone around the implant apex.

Table 3. Peak tensile and compressive stresses (MPa) and maximum strain $(\mu \mathrm{m})$ in the crestal cortical, trabecular, and apical cortical bone measured under eccentric loading simulations.

\begin{tabular}{lcccc}
\hline Region & Model & $\begin{array}{c}\text { Peak tensile } \\
\text { stress }\end{array}$ & $\begin{array}{c}\text { Peak } \\
\text { compressive } \\
\text { stress }\end{array}$ & Strain \\
\hline $\begin{array}{l}\text { Crestal } \\
\text { cortical }\end{array}$ & SW & 86.8 & 56.6 & 0.0045 \\
bone & SO & $24.6^{*}$ & 34.1 & $0.0016^{*}$ \\
& BO & 67.4 & $199.2^{*}$ & 0.0048 \\
Trabecular & BW & 66.6 & 127.4 & 0.0038 \\
bone & SO & 85.2 & 65.6 & $0.2210^{*}$ \\
& BO & 60.9 & 54.3 & 0.1460 \\
& BW & $12.9^{*}$ & $17.6^{*}$ & 0.10750 \\
Apical & SW & $124.2^{*}$ & $527.8^{*}$ & $0.0167^{*}$ \\
cortical & SO & 6.6 & 6.7 & 0.0026 \\
bone & BO & 14.4 & 14.9 & 0.0005 \\
& BW & 24.3 & 61.5 & 0.0014 \\
\hline
\end{tabular}

$\mathrm{SW}=$ subcrestal implant with apex anchored in cortical bone; $\mathrm{SO}=$ subcrestal implant anchored only in trabecular bone; $\mathrm{BO}=$ bone level implant anchored only in the crestal cortical bone; $\mathrm{BW}=$ bone level implant with bicortical fixation; *indicates a significant difference between models.
Although there is no clinical evidence on the level of stress at which bone remodeling ceases and resorption begins,$^{20}$ the ultimate bone strength is assumed to be the physiological limit of the cortical bone. ${ }^{12}$ Moreover, the peak compressive stress has been found to provide more reliable information in the analysis of bone resorption compared with the peak tensile stress. ${ }^{10}$ Therefore, bone resorption due to overloading should be expected when the compressive stress exceeds 100 to $130 \mathrm{MPa}$ in the cortical bone. ${ }^{21}$

In the present study, the implant placed at the crestal level (BO model) exerted a peak compressive stress of $233.9 \mathrm{MPa}$ under centric loading, which is above the physiological limit for cortical bone tissue. This can explain the common clinical findings of crestal bone loss around the implant neck and the report of higher failure rates for implants placed in the posterior maxilla. ${ }^{19}$ All other models exhibited safer values of compressive stress under centric loading: 44.3, 18.8, and 78.1 MPa for the SW, SO, and BW models, respectively. However, under eccentric loading, only the SW and SO models presented safe values. This decrease in compressive stress and strain in the crestal region can explain some clinical findings of bone ingrowth coronal to the fixture-abutment interface ${ }^{6}$ and a higher success rate with an increase in the depth of placement. ${ }^{22}$ 


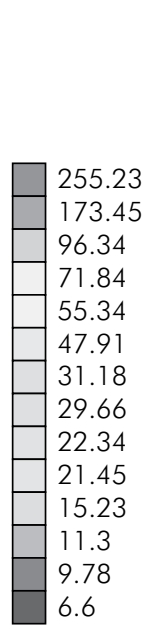

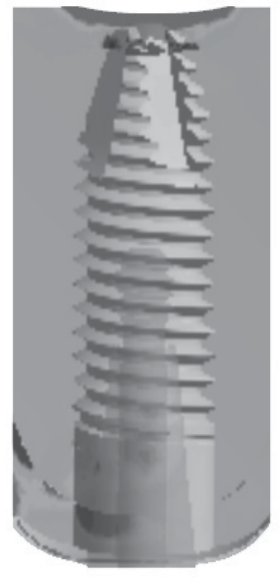

Model SW

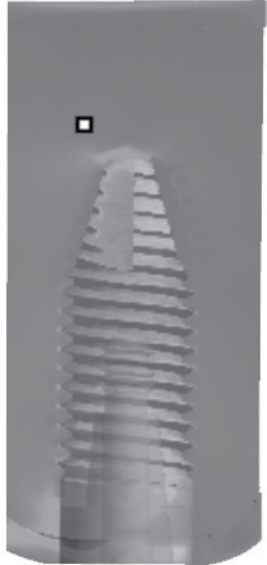

Model SO

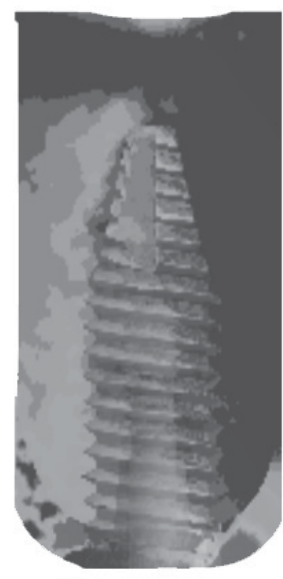

Model BO

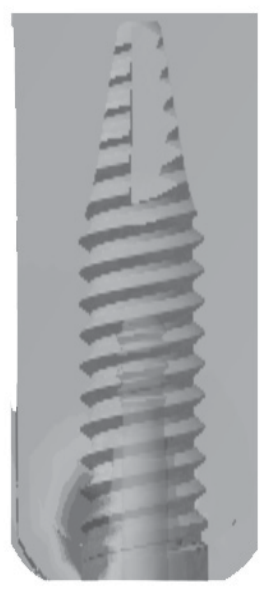

Model BW

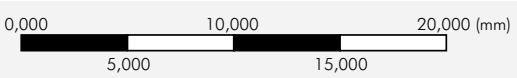

Figure 3. Compressive stress (MPa) around implants with different anchorage designs under eccentric loading.

This study was the first, as per our knowledge, to evaluate apical cortical bone anchorage for subcrestal implants. When the SW and SO models were compared, a shift in the stress and strain around the implant apex was evident in the SW model, confirming that stresses are primarily dissipated through the cortical bone. ${ }^{21}$ This was most evident when the implants were subjected to eccentric loading, during which the higher compressive stress and strain around the implant apex can be a consequence of a greater lever arm due to the displacement of the fulcrum to the apical region. ${ }^{23}$ Moreover, the tapered

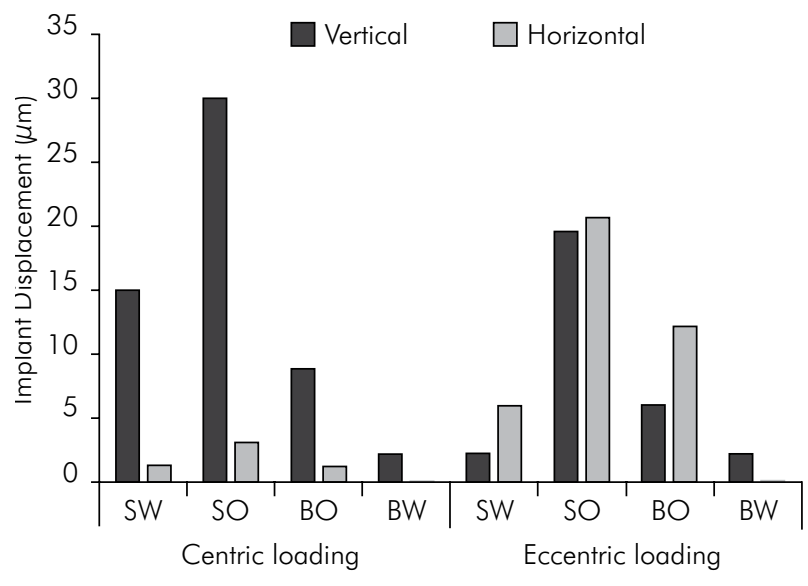

Figure 4. Vertical and horizontal implant displacement $(\mu \mathrm{m})$ during centric and eccentric loading simulations. apex decreases the surface area available to dissipate the stress, explaining the high stress and strain in the apical region and highlighting the importance of macrodesign on stress distribution around immediately loaded implants. ${ }^{17}$ This may not be critical because the resistance to fatigue failure in the cortical bone is greater during compression than during tension. ${ }^{24}$ Deposition and resorption of the bone matrix can be regulated by the mechanical environment; ${ }^{25}$ therefore, possible remodeling of the cortical bone around the implant apex should be assessed in future in vivo studies or clinical trials.

With regard to tensile stress, however, theSW model showed higher values in all bone regions compared with the other models. It was previously shown that tensile stress can induce ossification by increasing the expression of bone morphogenetic protein (BMP)-2 and BMP-4, which are bone growth factors. ${ }^{25}$ Therefore, this residual tensile stress can also explain why there is bone formation above the implant platform when the implants are placed subcrestally. ${ }^{6}$ On the other hand, this can be the consequence of the assumption that cortical and trabecular bones are homogeneous and perfectly bonded in the analysis because the implant platform is only $1 \mathrm{~mm}$ away from the trabecular/cortical interface. Because there is no threshold value to stimulate bone apposition, and because excessive ten- 
sile stress reportedly causes bone resorption, ${ }^{26}$ loading forces should be controlled by careful occlusal adjustments to avoid bone resorption.

Both subcrestal models were more efficient in decreasing the strain in the crestal region compared with the model with bicortical fixation. However, the strain generated was above the value considered risky for bone fracture; furthermore, it is difficult to estimate cellular and tissue responses to different levels of strain. ${ }^{27}$ Moreover, the subcrestal implant positioned only in the trabecular bone produced the lowest stress and strain in all evaluated regions. The low elastic modulus of trabecular bone acts as a stress breaker that promotes better dissipation of stresses from the occlusal loading. ${ }^{28}$

However, the peak stress was substituted by higher implant displacement. In the present study, all models exhibited implant displacement below the threshold of $150 \mu \mathrm{m}$ required to prevent fibrous tissue formation; ${ }^{2}$ these are in the same range reported by a previous study using FEA. ${ }^{29}$ However, previous in vitro studies reported displacement values of 100 to $340 \mu \mathrm{m}$ in type IV bone samples, ${ }^{30}$ which were above the stated threshold.

\section{References}

1. Javed F, Romanos GE. The role of primary stability for successful immediate loading of dental implants. A literature review. J Dent. 2010 Aug;38(8):612-20.

2. Szmukler-Moncler S, Salama H, Reingewirtz Y, Dubruille JH. Timing of loading and effect of micromotion on bone-dental implant interface: review of experimental literature. J Biomed Mater Res. 1998 Summer;43(2):192-203.

3. Devlin H, Horner K, Ledgerton D. A comparison of maxillary and mandibular bone mineral densities. J Prosthet Dent. 1998 Mar;79(3):323-7.

4. Tran BL, Chen ST, Caiafa A, Davies HM, Darby IB. Transmucosal healing around peri-implant defects: crestal and subcrestal implant placement in dogs. Clin Oral Implants Res. 2010 Aug;21(8):794-803.

5. Hammerle $\mathrm{CH}$, Bragger U, Burgin W, Lang NP. The effect of subcrestal placement of the polished surface of ITI implants on marginal soft and hard tissues. Clin Oral Implants Res. 1996 Jun;7(2):111-9.

6. Donovan R, Fetner A, Koutouzis T, Lundgren T. Crestal bone changes around implants with reduced abutment diameter placed non-submerged and at subcrestal positions: a 1-year radiographic evaluation. J Periodontol. 2010 Mar;81(3):428-34.
The limitation of the present study was that the trabecular bone was considered to be a uniform and homogeneous material. It is important to consider the morphology and density of the trabeculae in trabecular bone to determine its biomechanical influence on subcrestal implants. Future studies should evaluate the effects of possible remodeling around the apex on the success of subcrestal implants.

\section{Conclusions}

Subcrestal implant placement decreases the stress in the crestal cortical bone around dental implants, regardless of apical anchorage; however, apical cortical anchorage can be effective in limiting implant displacement.

\section{Acknowledgments}

This study was supported by Fundação de Amparoà Pesquisa doEstado deSãoPaulo(FAPESPno. 2011/22231-9) and the Conselho Nacional de Desenvolvimento Científico e Tecnológico (CNPq no. 159946/2011-5). The authors give a special thanks to Dr. Carlos Murgel (Campinas, Brazil) for providing the tomographic images.
7. Barros RR, Novaes Jr. AB, Muglia VA, Lezzi G, Piattelli A. Influence of interimplant distances and placement depth on peri-implant bone remodeling of adjacent and immediately loaded morse cone connection implants: a histomorphometric study in dogs. Clin Oral Implants Res. 2010 Apr 1;21(4):371-8.

8. Huang B, Meng H, Piao M, Xu L, Zhang L, Zhu W. Influence of placement depth on bone remodeling around tapered internal connection implant: a clinical and radiographic study in dogs. J Periodontol. 2012 Sep;83(9):1164-71.

9. Canullo L, Pace F, Coelho P, Sciubba E, Vozza I. The influence of platform switching on the biomechanical aspects of the implant-abutment system. A three dimensional finite element study. Med Oral Patol Oral Cir Bucal. 2011 Sep;16(6):e852-6.

10. Huang CC, Lan TH, Lee HE, Wang $\mathrm{CH}$. The biomechanical analysis of relative position between implant and alveolar bone: finite element method. J Periodontol. 2011 Mar;82(3):489-96.

11. Chou HY, Muftu S, Bozkaya D. Combined effects of implant insertion depth and alveolar bone quality on periimplant bone strain induced by a wide-diameter, short implant and a narrowdiameter, long implant. J Prosthet Dent. 2010 Nov;104(5):293-300. 
12. Baggi L, Cappelloni I, Di Girolamo M, Maceri F, Vairo G. The influence of implant diameter and length on stress distribution of osseointegrated implants related to crestal bone geometry: a three-dimensional finite element analysis. J Prosthet Dent. 2008 Dec;100(6):422-31.

13. Ahn SJ, Leesungbok R, Lee SW, Heo YK, Kang KL. Differences in implant stability associated with various methods of preparation of the implant bed: an in vitro study. J Prosthet Dent. 2012 Jun;107(6):366-72.

14. Katranji A, Misch K, Wang HL. Cortical bone thickness in dentate and edentulous human cadavers. J Periodontol. 2007 May;78(5):874-8.

15. Ausiello P, Apicella A, Davidson CL. Effect of adhesive layer properties on stress distribution in composite restorations--a 3D finite element analysis. Dent Mater. 2002 Jun;18(4):295-303.

16. Sevimay M, Turhan F, Kilicarslan MA, Eskitascioglu G. Three-dimensional finite element analysis of the effect of different bone quality on stress distribution in an implantsupported crown. J Prosthet Dent. 2005 Mar;93(3):227-34.

17. Huang HL, Hsu JT, Fuh LJ, Lin DJ, Chen MY. Biomechanical simulation of various surface roughnesses and geometric designs on an immediately loaded dental implant. Comput Biol Med. 2010 May;40(5):525-32.

18. Hattori Y, Satoh C, Kunieda T, Endoh R, Hisamatsu H, Watanabe $M$. Bite forces and their resultants during forceful intercuspal clenching in humans. J Biomech. 2009 Jul 22;42(10):1533-8.

19. Clelland NL, Lee JK, Bimbenet OC, Gilat A. Use of an axisymmetric finite element method to compare maxillary bone variables for a loaded implant. J Prosthodont. 1993 Sep;2(3):183-9.

20. Frost HM. A 2003 update of bone physiology and Wolff's law for clinicians. Angle Orthod. 2004 Feb;74(1):3-15.

21. Natali AN, Hart RT, Pavan PG, Knets I. Mechanics of bone tissue. In: Natali AN, editor. Dental biomechanics. London: Taylor \& Francis; 2003. p. 1-19.
22. Lee EH, Ryu SM, Kim JY, Cho BO, Lee YC, Park YJ, et al. Effects of installation depth on survival of an hydroxyapatite-coated bicon implant for single-tooth restoration. J Oral Maxillofac Surg. 2010 Jun;68(6):1345-52.

23. Weinberg LA. Reduction of implant loading using a modified centric occlusal anatomy. Int J Prosthodont. 1998 JanFeb;11(1):55-69.

24. Carter DR, Caler WE, Spengler DM, Frankel VH. Fatigue behavior of adult cortical bone: the influence of mean strain and strain range. Acta Orthop Scand. 1981 Oct;52(5):481-90.

25. Sato M, Ochi T, Nakase T, Hirota S, Kitamura Y, Nomura S, et al. Mechanical tension-stress induces expression of bone morphogenetic protein (BMP)-2 and BMP-4, but not BMP-6, BMP-7, and GDF-5 mRNA, during distraction osteogenesis. J Bone Miner Res. 1999 Jul;14(7):1084-95.

26. Carter DR. Mechanical loading histories and cortical bone remodeling. Calcif Tissue Int. 1984;36 Suppl 1:S19-24.

27. Frost HM. The role of changes in mechanical usage set points in the pathogenesis of osteoporosis. J Bone Miner Res. 1992 Mar;7(3):253-61.

28. Morris HF, Ochi S, Crum P, Orenstein IH, Winkler S. AICRG, Part I: a 6-year multicentered, multidisciplinary clinical study of a new and innovative implant design. J Oral Implantol. 2004 Jun;30(3):125-33.

29. Chang PK, Chen YC, Huang CC, Lu WH, Chen YC, Tsai HH. Distribution of micromotion in implants and alveolar bone with different thread profiles in immediate loading: a finite element study. Int J Oral Maxillofac Implants. 2012 Nov-Dec;27(6):e96-101.

30. Engelke W, Decco OA, Rau MJ, Massoni MC, Schwarzwaller W. In vitro evaluation of horizontal implant micromovement in bone specimen with contact endoscopy. Implant Dent. 2004 Mar;13(1):88-94. 